\title{
Bentonite Exposure in Western Pacific Amyotrophic Lateral Sclerosis/ Parkinsonism Dementia Complex and Neurodegenerative Diseases
}

Kavitha Reddy, M.D.

Harvard Vanguard Medical Associates, Boston, Massachusetts

Email: kreddy@bu.edu

Keywords: neurodegeneration, protein misfolding, Western Pacific, Guam, montmorillonite, bentonite, clay, mineral, ALS, Parkinson's disease

\begin{abstract}
Neurodegenerative diseases of protein misfolding affect humans and animals. In humans, these diseases include Alzheimer's disease (AD), Parkinson's disease (PD), amyotrophic lateral sclerosis (ALS), and Western Pacific amyotrophic lateral sclerosis and Parkinsonism-dementia complex (ALS/PDC). Mineral exposure may be important in the pathogenesis of protein misfolding cascades. The possible association of bentonite, montmorillonite, and mineral risk factors with Alzheimer's disease, Parkinson's disease, ALS, and Western Pacific ALS/PDC is analyzed and discussed.
\end{abstract}




\section{Introduction}

Western Pacific amyotrophic lateral sclerosis and Parkinsonism-dementia complex (ALS/PDC) is a notable member of the group of human protein misfolding diseases. The disease has presented in individuals in Guam, the Kii peninsula of Japan, and Western Guinea. ${ }^{1}$ Though only small geographic areas and a limited number of individuals have been affected, the disease has been the subject of intense scientific interest because of its devastating course, high prevalence in an isolated community, overlapping phenotype with a variety of more common protein misfolding diseases, and the historic consensus that an environmental or modifiable cause might be found. ${ }^{2}$ Despite many years of study, it has remained an enigma. An improved understanding of Western Pacific ALS/PDC, or indeed any of the protein misfolding diseases Alzheimer's disease, Parkinson's disease, and amyotrophic lateral sclerosis, may reveal clues to aid in decryption of the entire disease group. Therefore Western Pacific ALS/PDC has been called the "Rosetta Stone" of protein misfolding disease.

\section{Western Pacific ALS/PDC}

Individuals affected with Western Pacific ALS/PDC show symptoms and signs of amyotrophic lateral sclerosis, parkinsonism-dementia, or an overlap of both phenotypes. ${ }^{1}$ In Guam, the disease is commonly called lytico-bodig. The preponderance of data strongly suggests an environmental cause. In this manuscript, I suggest that mineral exposure such as bentonite exposure may be a primary factor in Western Pacific ALS/PDC. A potential role for montmorillonite, a bentonite mineral, in protein misfolding has been described in a previous paper. ${ }^{3}$

The island of Guam has a rich volcanic history, resulting in the presence of a variety of minerals in its rocks and soil. Study of historic records reveals there are significant sources of minerals in areas of potential human exposure. $4,5 \mathrm{~A}$ report written for the U.S. Commercial Company in 1946, near the peak of the lytico-bodig epidemic, recognizes the presence of volcanic agglomerate and tuff, and its weathering products, in Guam. ${ }^{4}$ Red tuff and red soil are associated with these formations. Manganese and pyrolusite are also reported, among other minerals. The document also contains a description of likely bentonites in southern Guam. ${ }^{4}$ In the survey, the following is described:

"Certain plastic clays believed to be bentonites were...in two localities on Guam. Similar clays very likely exist at other localities on the southern portion of the island wherever volcanic tuffs are exposed, from which formation of the clays have been derived. Such clays were first noted in the area presently occupied by the large Naval Ammunition Depot southeast of Santa Rita in the savanna-like basin south and east of the springs which are the source of the water pumped to the reservoir on the hill a short distance east of Santa Rita village. This area is south of the old community of Bona, and its center is about 2000 yards east of Mt. Alifan in an area 
characterized by grass-covered rolling hills now traversed by a network of winding roads along which revetments have been built for storing ammunition. In this area, which is all underlain by fine-grained volcanic tuffs, an observer may note that after a shower, where the surface is bare of vegetation, thin crusts of wetted clay will arch upwards separating itself from the underlying dryer clay. This phenomenon is particularly characteristic of bentonite because of its peculiar property of expanding substantially when wetted. Bentonites also have the peculiar property of remaining suspended in water indefinitely, instead of settling to the bottom as do ordinary clays...The second locality known to the writer where clay, believed to be bentonite, was noted is near the southeastern corner of Apra Harbor... Another exposure of similar material may be seen in a nearby highway cut."

- William D. Mark. Report on Mineral Resources of Micronesia, U.S. Commercial Company, Economic Survey. Honolulu, October $1946^{4}$

In addition, geological information published in 1964 confirms numerous areas of montmorillonite, zeolite, and other minerals on the island. ${ }^{5}$ It should be noted that the Western Pacific region, like its member island Guam, also has a rich volcanic and geologic history, which provides a source of diverse and abundant minerals, many of which are less commonly exposed or encountered in other parts of the world. The area of the Kii peninsula in Japan affected with Western Pacific ALS/PDC also appears to contain Fuller's earth (bentonite), accretionary wedges that can contain several mineral types, and other exposed mineral resources. ${ }^{6}$ This provides a common environmental factor between the observed sites of Western Pacific ALS/PDC. Bentonites, zeolites, and other minerals associated with weathered volcanic rocks are more abundant in southern Guam, which may provide a possible explanation for the concentration of lytico-bodig disease in the southern region.

Until approximately 1910, water on southern Guam was typically obtained by hand collection from springs, rain catchments, and wells. ${ }^{7}$ Most of the available freshwater comes from surface water that runs over weathered volcanic rocks. ${ }^{8}$ Between 1937 and 1941, water from the Alamagosa springs began to be routed to the reservoir system. ${ }^{7}$ The Maanot reservoir was used as a significant municipal water source in 1941, and was re-established as a primary source after the end of Japanese occupation in 1944. This later became part of the Fena reservoir system, which is still in use today. ${ }^{7}$ As development continued, in 1950 the authority to administer utilities was granted to the Department of Public Works, and in 1952, the Public Utility Agency of Guam was created. ${ }^{9}$ The peak of the documented epidemic of lytico-bodig occurred in the approximate range of 1950-1960. ${ }^{10}$ Given that neurodegenerative diseases such as lytico-bodig might have a substantial latency period, the exposure peak may have been before the major water development initiatives of the 1940's and 1950's. As Western Pacific ALS/PDC began to decrease at the time that water supplies to the public began to be more extensively developed and managed, the possibility is raised that either changes to the water supply, diversification of sources or mixing from unaffected sources, or other features of development may have led to a decrease in exposure to the disease agent. One might consider whether some of the varied water sources used before and up to 1910 
might have contained clay minerals. One might also consider whether the Alamagosa springs, Maanot reservoir or other nearby water sources might contain or have contained clay minerals. In addition one may consider if in fact their development, providing an alternative to the varied previous water sources, and perhaps adding the use of water filtration or treatment, may have in fact reduced exposure to the agent of Western Pacific ALS/PDC. In addition to these significant changes to the water supply, the Fena land area itself was increasingly used by the Navy after 1944 and closed by the U.S. Federal Government to public access by $1950^{11}$, reducing exposure to the bentonites likely located on this land.

Linear retinal pigment epitheliopathy (LRPE) is another condition unique to the Western Pacific region, and one that frequently overlaps with ALS/PDC. ${ }^{12}$ LRPE shows linear or worm-like areas of depigmentation of the retinal pigment epithelium. ${ }^{12}$ The differential diagnosis includes parasitic infection, however larvae are not found, and the condition has a number of dissimilarities when compared with any known parasitic infection in the world. ${ }^{12}$ There are many unusual features of LRPE that expand the differential diagnosis beyond parasitic infection, and the causative agent remains unknown. The retina receives connections from the brain including from the thalamus and adjacent regions. The RPE is provided a regular daily rich source of fatty acids. ${ }^{13}$ Lipid vesicles can elongate to form long filamentous structures as they grow. ${ }^{14} \mathrm{~A}$ "pearling" phenomenon has been observed with lipid vesicle growth and division. ${ }^{14}$ The pattern of LRPE may be similar to the induced growth of lipid vesicles, showing long, tube- or worm-like structures, with occasional areas that appear to have a spherical bulge or spherical component. One may consider the possibility that lipid vesicles such as those catalyzed by montmorillonite, zeolites, or other minerals, are present in LRPE or lytico-bodig as hypothesized may be present in prion disease. ${ }^{3}$ LRPE is a very difficult phenomenon to explain and the identification of its cause will likely provide new medical insights.

\section{Alzheimer's disease}

As it has been hypothesized that mineral exposure may have a significant role in the natural pathogenesis of protein misfolding disease ${ }^{3}$, potential exposures to montmorillonite and clay minerals in other neurodegenerative diseases of protein misfolding are analyzed and discussed below. Environmental exposures are considered important in this group of diseases. There are suggestions that minerals may play a role in Alzheimer's disease. For example, aluminosilicates have been found in Alzheimer's disease plaques. ${ }^{15}$ Having the occupation of teacher has been implicated as a major risk factor for Alzheimer's disease, Parkinson's disease, and ALS. ${ }^{16}$ One may consider whether exposure to chalk, for example due to minerals in chalk, or to paper, for which minerals are used in production, could be a common factor. Clergy were also found at higher risk of neurodegenerative disease. ${ }^{16}$ Clergy may share some exposures with teachers, as teaching is a frequent aspect of the religious services provided. Hairdressers have also been found to be at significantly higher risk of neurodegenerative disease ${ }^{16}$ Here one may consider whether bentonites, for example in hair lightening powders and other hair care powders and 
products, may be an exposure source. All possible etiologies may be considered until this most common of the neurodegenerative diseases is understood.

\section{Parkinson's disease}

Some studies have shown an increased Parkinson's disease risk in those who have consumed well water. ${ }^{17}$ A higher rate of association with Parkinson's disease was seen for those wells near to possible pesticide exposures, particularly with certain pesticides. ${ }^{17}$ The pesticide in the study with the highest association with Parkinson's disease risk was propargite (brand name Omite). ${ }^{17}$ In addition, farm work, rural living, and working with pesticides have all been considered as a possible risk factors for Parkinson's disease. One may consider whether clay content in well water, such as colloidal clay, is a risk factor. The factors may share overlapping traits of possible well water exposure to clay, clay/mineral inhalation or ingestion, and/or pesticide exposure. Interestingly, propargite, and many pesticides have mineral ingredients and carriers. A review of Omite 30WS ingredients shows $20-30 \%$ concentration of kaolin. ${ }^{18}$ Kaolin shares several features with montmorillonite and might promote protein misfolding effects as hypothesized. ${ }^{3}$ In addition, kaolin products often contain a percentage of montmorillonite. Omite also contains diatomaceous earth (largely silica), which again can have some montmorillonite and other minerals within it, and Omite also contains silica gel, quartz, and cristobalite. ${ }^{18}$ In addition, the active ingredient of pesticides themselves often have neurotoxic effects and these could be a source of either primary or synergistic damage in Parkinson's disease.

\section{Amyotrophic Lateral Sclerosis}

Studies have shown occupational risk factors for ALS include work as a potter, tile or glass worker. ${ }^{19}$ One must consider that these workers may have been exposed to minerals such as bentonites, which have been used in pottery throughout history. A study in Italy also showed an association of ALS with the occupation of bank teller. ${ }^{20}$ Interestingly, the occupation of bank teller was also associated with Alzheimer's disease, another protein misfolding disease, in a different study. ${ }^{16}$ While this may seem to be a perplexing risk factor, one might consider whether exposure to carbon copy paper or processed paper could be an associated cause. Carbon copy paper contains kaolin or clay minerals. The Italian study which found an association with the occupation of bank teller also found a lesser association with the jobs of general practitioner and of sales representative. ${ }^{20}$ One might speculate as to whether these occupations could all be linked by the common risk factor of carbon copy paper or heavy paper exposure. ALS has also been seen in some athletes. A study found a severely increased risk of ALS among Italian soccer players. ${ }^{21}$ Another study found an increased risk of ALS and Alzheimer's disease in retired National football league (NFL) American football players as well. ${ }^{22}$ The lines used to mark soccer and football fields have contained clay or chalk in the past. A cluster of ALS cases has been found in the region of Enfield, New Hampshire, near Lake Mascoma. ${ }^{23}$ Investigation into the mineral 
history of the area reveals that alluvial, glacial and other silts and clays are likely in the area. ${ }^{24}$ Possible exposure routes could include presence in the drinking water supply, well water exposure, lake water exposure, or exposure to clay minerals on land or in air. Lastly, some studies have found that veterans and members of the military may have higher rates of ALS. ${ }^{25}$ The military water supply, some of which may involve wells or aquifers, or other sources which might contain clay minerals, exposure to clay in the base or active duty environment, or exposure to military bentonite desiccants are potential links to be considered between ALS and a military history. One may consider whether mineral exposures could be a potential cause of increased rates of ALS in varied situations.

Aluminosilicates and other minerals are commonly added to an immense variety of products that individuals are regularly exposed to in the course of everyday living, such as salts, spices, food additives, cosmetic products, and other items. The effect of these exposures is likely varied by the mineral type, amount, and length of exposure. In addition to the above suggestions that mineral exposures could be associated with disease, there is also evidence of tolerance of many mineral exposures without negative effects. For example, kaolin from the state of Georgia in the United States has been consumed sometimes daily for years by many individuals, without obvious or documented development of neurodegenerative disease. Nonetheless, the effect of bentonites such as montmorillonite, zeolites, and other minerals, particularly in the form of small particles or of minerals dissolved in water might be explored, along with other possible etiologies of neurodegenerative diseases. Continued exploration of hypotheses could one day lead to an understanding of Western Pacific ALS/PDC, a condition that is rare, fascinating, and rapidly becoming "extinct". Without a full understanding of the condition, the epidemic of Western Pacific ALS/PDC may experience a resurgence in the Western Pacific region in the future or may appear in other parts of the globe. The minerals present in the affected areas of the Western Pacific are naturally present in other locations as well, including other islands, the mainland United States and other countries in the worldwide community. In summary, bentonite and mineral exposure may be the cause or a key factor in Western Pacific ALS/PDC and other neurodegenerative diseases. Further study is encouraged of its potential role in this mysterious and devastating group of diseases. 


\section{References}

1. Kisby GE, Spencer PS. Is neurodegenerative disease a long-latency response to early-life genotoxin exposure? Int J Environ Res Public Health, 8, 3889-3921 (2011).

2. Miklossy J, Steele JC, Yu S, McCall S, Sandberg G, McGeer EG, McGeer PL. Enduring involvement of tau, beta-amyloid, alpha-synuclein, ubiquitin, and TDP-43 pathology in the amyotrophic lateral sclerosis/Parkinsonism-Dementia complex of Guam (ALS/PDC). Acta Neuropathol 116 (6): 625-37 (2008).

3. Reddy K. Beyond the protein-only hypothesis: A novel mineral-lipid hypothesis in prion and protein-misfolding disease. Peer J Preprints (2017).

4. Mark, WD. Report on Mineral Resources of Micronesia. U.S. Commercial Company, Economic Survey (1946).

5. Tracey JI, Schlanger SO, Stark JT, Doan DB, May HG. General Geology of Guam. U.S. Geological Survey Professional paper 403-A (1964).

6. Takagi, T. Bentonite in Japan- Geology and Industries. Geological Survey of Japan no. 425 (2005).

7. Reed R. Historic American Engineering Record, U.S. Naval Base, Guam Munitions Site, Maanot Reservoir, HAER No. GU-7. (2011)

8. Gingerich, SB. Water-Resources Investigation Report 03-4126. U.S. Geological Survey (2003).

9. United States Environmental Protection Agency. Inspection and Sanitary Survey Report for the Guam Waterworks Authority Public Water System. Guam, United States Territory, April 23-May 4, 2012.

10. Plato CC, Garruto RM, Galasko D. Craig U, Plato M, Gamst A, Torres JM, Wiederholt W. Amyotrophic Lateral Sclerosis and Parkinsonism-Dementia Complex of Guam: Changing Incidence Rates during the Past 60 Years. Am J Epidemiol 157: 149-157 (2003).

11. Fena. Guampedia. https://www.guampedia.com/heritage-site-fena/

12. Steele JC. The association of linear retinal pigment epitheliopathy (LRPE) and the parkinsonism-dementia complex of of Guam and Japan (ALS/PDC): A final progress report to the board of directors (2008).

13. Adijanto J, Du J, Moffat C, Seifert E, Hurley JB, Philp NJ. The retinal pigment epithelium utilizes fatty acids for ketogenesis. Journal of Biological Chemistry, 289 (30): 20570-20582 (2014). 
14. Zhu T, Szostak JW, Coupled growth and division of model protocell membranes. J Am Chem Soc 131: 5705-5713 (2009).

15. Candy JM, Klinowski J, Perry RH, Fairbairn A, Oakley AE, Carpenter TA, Atack JR, Blessed G, Edwardson JA. Aluminosilicates and senile plaque formation in Alzheimer's disease. Lancet, 1, 354-357 (1986).

16. Park RM, Schulte PA, Bowman JD, Walker JT, Bondy SC, Yost MG, Touchstone JA, Dosemeci M. Potential occupational risk for neurodegenerative diseases. Am J Ind Med. 48:63-77 (2005).

17. Gatto NM, Cockburn M, Bronstein J, Manthripragada AD, Ritz B. Well-water consumption and Parkinson's disease in rural California. Environmental health perspectives. 117 (12): 1912-1918 (2009).

18. Omite 30WS Safety Data Sheet https://assets.greenbook.net/M29965.pdf

19. Peters TL, Kamel F, Lundholm C, Feychting M, Weibull CE, Sandler DP, Weibert P, Sparen P, Ye W, Fang F. Occupational exposures and the risk of amyotrophic lateral sclerosis. Occup Environ Med 74(2): 87-92 (2017).

20. D’Ovidio F, d'Errico A, Calvo A, Costa G, Chio A. Occupations and amyotrophic lateral sclerosis: are jobs exposed to the general public at higher risk? European Journal of Public Health 27(4): 643-647 (2017).

21. Chio A, Benzi G, Dossena M, Mutani R, Mora G. Severely increased risk of amyotrophic lateral sclerosis among Italian professional football players. Brain 128:472-6 (2005).

22. Lehman EJ, Hein MJ, Baron SL, Gersic CM. Neurodegenerative causes of death among retired National Football League players. Neurology 79: 1970-1974 (2012).

23. Caller TA, Doolin, JW, Haney JF, Murby AJ, West KG, Farrar HE, Harris BT, Stommel EW, A cluster of amyotrophic lateral sclerosis in New Hampshire: A possible role for toxic cyanobacteria blooms. Amyotroph Lateral Scler 10: 101-8 (2009).

24. City of Lebanon, New Hampshire. Rock and Soil Report. https://lebanonnh.gov/DocumentCenter/View/899/Foundations---Rock-Soil-andWater-PDF?bidId= . Accessed May 2020.

25. Beard JD, Kamel F. Military service, deployments, and exposures in relation to amyotrophic lateral sclerosis etiology and survival. Epidemiol Rev 37(1): 55-70 (2015). 